\title{
Article \\ Evaluating Impact Damage of Flat Composite Plate for
Surrogate Bird-Strike Testing of Aeroengine Fan Blade
}

\author{
Youchao Sun ${ }^{1, * \mathbb{D}}$, Yuemei Zhang ${ }^{1,2}$, Yadong Zhou ${ }^{1, * \mathbb{C}}$, Haitao Zhang ${ }^{3}$, Haijun Zeng ${ }^{4}$ and Kun Yang ${ }^{4}$ \\ 1 College of Civil Aviation, Nanjing University of Aeronautics and Astronautics, Nanjing 211100, China; \\ zhangyuemei@comac.cc \\ 2 Commercial Aircraft Corporation of China, Ltd., Shanghai 200126, China \\ 3 Shanghai Aircraft Airworthiness Certification Center, Shanghai 200335, China; zhanghaitao_hd@caac.gov.cn \\ 4 Commercial Aircraft Engine Co., Ltd., Aero Engine Cooperation of China, Shanghai 201100, China; \\ zenghaijun@yeah.net (H.Z.); yangk@acae.com.cn (K.Y.) \\ * Correspondence: sunyc@nuaa.edu.cn (Y.S.); yzhou@nuaa.edu.cn (Y.Z.)
}

Citation: Sun, Y.; Zhang, Y.; Zhou, Y.;

Zhang, H.; Zeng, H.; Yang, K.

Evaluating Impact Damage of Flat

Composite Plate for Surrogate

Bird-Strike Testing of Aeroengine Fan

Blade. J. Compos. Sci. 2021, 5, 171.

https://doi.org/10.3390/jcs5070171

Academic Editor:

Francesco Tornabene

Received: 23 May 2021

Accepted: 25 June 2021

Published: 30 June 2021

Publisher's Note: MDPI stays neutral with regard to jurisdictional claims in published maps and institutional affiliations.

Copyright: () 2021 by the authors. Licensee MDPI, Basel, Switzerland. This article is an open access article distributed under the terms and conditions of the Creative Commons Attribution (CC BY) license (https:// creativecommons.org/licenses/by/ $4.0 /)$.
Abstract: Bird-strike failure of fan blades is one of the basic challenges for the safety of aircraft engines. Simplified flat blade-like plates are always used for damage mechanism study of composite laminates. One undesirable issue is the failure at the root of clamped flat plates under high-velocity impact. For this purpose, two different strategies were exploited to obtain desirable impact damage distributions, namely the impact location and the boundary condition. Numerical models of the simplified flat blade-like plate and the bird projectile were constructed by using finite element method (FEM) and smoothed particle hydrodynamics (SPH) approaches. The impact damage distributions were comparatively investigated in detail. The numerical results show that changing the boundary condition is the most effective way to obtain preferable impact damages for further failure analysis of real fan blades. Present results will be useful to the future surrogate experimental design of simplified bird-strike testing.

Keywords: bird strike; impact damage; composite plate; SPH/FEM simulation; fan blade

\section{Introduction}

Airworthiness certification, of aircraft materials and structures subjected to bird strike, is an important issue for aviation safety [1-3]. Aircraft engines are the critical front-facing components, and the fan blades may be subjected to bird strike with high probability [1]. Demonstration of fan blade resistance against bird strikes is crucial structural criteria for an airworthiness certification by the Federal Aviation Administration (FAA) and other authorities. Meguid et al. [4] studied the impact behaviour of an artificial bird impinging a flexible aeroengine fan blade. Sinha [5] obtained transient response of a composite rotating airfoil under bird-slicing impact. Muir et al. [6] numerically investigated the structural response of bird-damaged fan blades, where realistic fan configuration was considered in numerical simulations. Liu et al. [7] carried out bird strike tests on the rotary engine primary compressor under different impact boundary conditions. Because of the high sensitivity to out-of-plane impact loadings, composite laminates exhibit a highly brittle response and usually dissipate a large amount of impact energy by the creation of new failure surfaces, such as the matrix cracks, delamination, fibre fracture, and fibre/matrix debonding, etc. The authors et al. [8] previously considered the bird-strike failure analysis of rotating laminated disks, where the rotation effect was addressed for future applications of the aeroengine system. Then, the authors et al. [9] also studied the impact responses of simplified blade-like composite plates. However, the impact damage was not evaluated therein. In addition, the symmetrical flat plates with the cantilever boundary condition were explored for the damage equivalency of the twisted composite blade [10]. 
The virtual testing of impacted composite structures is critically beneficial for both academic and industrial work [11]. The component-level study of impact damage in composites is highly critical $[12,13]$ so as to give insight into the local strain and microcracking behaviour $[14,15]$. It should be noted that bird strike of fan blades involves the problem regarding the angle of attack of the inclined airfoil [16], which complicates the issue, such as slicing of a bird by fan blades in the direction of the relative velocity. While dealing with composite laminates, full-scale complete tests of aeroengine fan blades become infeasible in the early design process due to the associated high cost. Cantilever slender plates are an important experimental configuration to examine the impact resistance of composite laminates to mimic real fan blades. Significant contributions have been made toward understanding the bird impact behaviours of these simplified plates. Hou et al. [17] simulated bird strike on composite panels by means of simple laboratory tests to provide data for the modelling and design of composite fan blades. For application to the bird-strike problem of composite fan blades, Nishikawa et al. [18] simplified a unidirectional composite plate for discussing the damage characteristics. They found the transition from the global bending mode, at low velocity, to the local deformation mode at high velocity. Handschuh et al. [19] developed the simplified test article geometry to realistically simulate a blade leading edge while decreasing fabrication complexity, where the prepared leading edge test article was clamped along one long edge. Liu et al. [20] carried out bird impact tests on the composite plates using the gas gun system. They divided the whole impact event into three stages, i.e., local deformation stage, post-flow impact stage, and bending deflection stage. Such specimen-level experiments can obtain some critical damage mechanisms for component-level failure analysis.

For the real complex twisted fan blades, under bird-strike impact, the most susceptible regions are always indicated to be the impact contact area and the leading edges of the blade [21], which can slice the bird projectile. Vignjevic et al. [21] presented that there was a strong influence of bird impact location on the extent of blade deformations. In terms of simplified blade-like components in experimental investigation, however, the maximum impact damages are always located at the root of cantilever flat plates [20], which is determined by the characteristic of the structure and loading types. The flat slender plates can be considered as thin beam-type structures, and hence the bending moments achieve the maximum at the clamped end under bending deformations. That is to say, a significant discrepancy exists in the most severely damaged locations between the real fan blades and simplified flat ones under bird impact loading. Evaluation of impact damage in simplified flat composite plate is still lacking in previous studies. Consequently, this study performs the bird-strike simulation of simplified flat composite plate with different boundary conditions and impact locations. The aim is to achieve a suitable damage distribution which can reflect the real loaded situation of a composite fan blade under bird-strike impact.

Figure 1 illustrates the role of plate-level study for bird-strike analysis of aeroengine fan blades. The aeroengine-level test is always time-consuming and high cost, especially for composite laminated fan blades. In the design stage, it is difficult to use the real blades of composite materials for try and error tests. The plate-level experimental study is promising to investigate the damage mechanism and impact loading capability. Therefore, the similarity between the simplified testing and real operating situation should be intensively considered. It will be highly beneficial to solve the damage similarity under bird strike, for purpose of the small-scale experiment, to replace a full-scale one. With the help of the structural similarity regarding the component-level experiments for complicated blades, the clamped flat plates can be successfully applied. Within such scenario, the aim of the present study is to obtain some simulation results to help future experiments be workable and useful. The main strategy is to consider different impact locations and to change the boundary conditions. By comparing the impact damage distributions under bird strike, the final goal is to obtain the desirable damage distributions of the simplified flat blade-like 
plates, which are similar with those in the real fan blades, rather than the undesirable failure at the clamped roots.

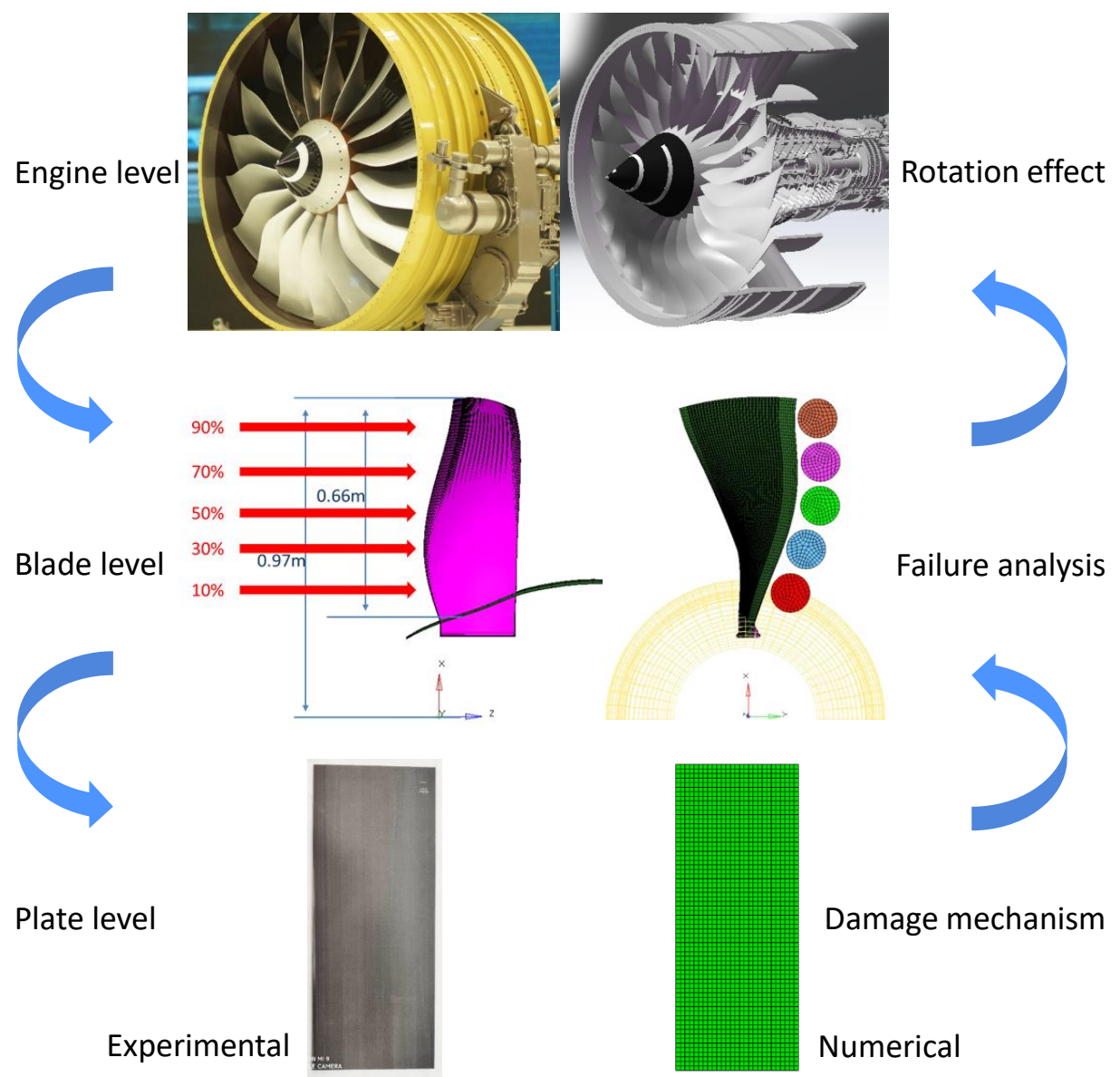

Figure 1. The role of plate-level study for bird-strike analysis of aeroengine fan blade.

\section{SPH/FEM Modelling and Simulation}

The cylindrical projectile was widely used to simulate the bird body [22], with the length-to-diameter ratio of 2. The smoothed particle hydrodynamics (SPH) method is applied to describe the bird's fluidic behaviour, at high-velocity impact, for present simulations. The flat laminated plates $(500 \mathrm{~mm} \times 200 \mathrm{~mm} \times 24 \mathrm{~mm})$ are modelled by the finite element method (FEM), with a total of 1809 linear quadrilateral elements of type S4R used in ABAQUS software. The total mass of the whole plate was $3.84 \mathrm{~kg}$. The stacking sequence of the unidirectional lamina of the simplified fan blade was $\left[0^{\circ} /-45^{\circ} / 0^{\circ} / 45^{\circ} / 45^{\circ} / 0^{\circ} /-45^{\circ} / 0^{\circ}\right]_{\mathrm{s}}$. The $0^{\circ}$ direction (longitudinal direction) was along the blade span. A total of 16 layers were used. The Hashin damage criterion was used to describe the material failure behaviours, which has been widely applied for in-plane damage analysis of composite laminates under impact loadings [8,23-25]. The Hashin damage criterion can consider four different damage modes: fibre tension, fibre compression, matrix tension, and matrix compression. Table 1 lists the mechanical properties of the unidirectional lamina for dynamic failure analysis in the present study.

Table 1. Mechanical properties of the unidirectional lamina.

\begin{tabular}{|c|c|c|c|c|c|}
\hline Elasticity & & Strength & & Fracture Energy & \\
\hline Young's Modulus, $\mathrm{E}_{11}(\mathrm{GPa})$ & 181 & Longitudinal tension, $\mathrm{X}^{\mathrm{T}}(\mathrm{MPa})$ & 1500 & Longitudinal tension, $\mathrm{G}_{1 \mathrm{c}}^{\mathrm{T}}\left(\mathrm{kJ} / \mathrm{m}^{2}\right)$ & 11.5 \\
\hline Young's Modulus, $\mathrm{E}_{22}(\mathrm{GPa})$ & 10.3 & Longitudinal compression, $\mathrm{X}^{\mathrm{C}}(\mathrm{MPa})$ & 1500 & Longitudinal compression, $G_{1 c}^{C}\left(\mathrm{~kJ} / \mathrm{m}^{2}\right)$ & 4.1 \\
\hline Shear Modulus, $\mathrm{G}_{12}(\mathrm{GPa})$ & 7.17 & Transverse tension, $\mathrm{Y}^{\mathrm{T}}(\mathrm{MPa})$ & 40 & Transverse tension, $\mathrm{G}_{2 \mathrm{c}}^{\mathrm{T}}\left(\mathrm{kJ} / \mathrm{m}^{2}\right)$ & 0.35 \\
\hline Shear Modulus, $\mathrm{G}_{13}(\mathrm{GPa})$ & 1 & Transverse compression, $\mathrm{Y}^{\mathrm{C}}(\mathrm{MPa})$ & 246 & Transverse compression, $\mathrm{G}_{2 \mathrm{c}}^{\mathrm{C}}\left(\mathrm{kJ} / \mathrm{m}^{2}\right)$ & 3.2 \\
\hline Shear Modulus, $\mathrm{G}_{23}(\mathrm{GPa})$ & 0.5 & Longitudinal shear, $\mathrm{S}^{\mathrm{L}}(\mathrm{MPa})$ & 200 & & \\
\hline Poisson's ratio, $v_{12}$ & 0.28 & Transverse shear, $\mathrm{S}^{\mathrm{T}}(\mathrm{MPa})$ & 123 & & \\
\hline
\end{tabular}


The explicit dynamic analysis was performed to simulate the impact process. A total of 2220 linear hexahedral elements of type C3D8R were created firstly for the bird projectile (geometric and mass details: length $=200$, diameter $=100 \mathrm{~mm}$, weight $=1.49 \mathrm{~kg}$ ), and then, these finite elements were converted to SPH particles as the explicit dynamic analysis began. Herein, the impact velocity of the bird projectile was $120 \mathrm{~m} / \mathrm{s}$. The SPH/FEM numerical model and simulation cases are as shown in Figure 2. The "hard" contact relationship was defined, which can minimize the penetration of the slave surface into the master surface at the constraint locations, and does not allow the transfer of tensile stress across the interface.

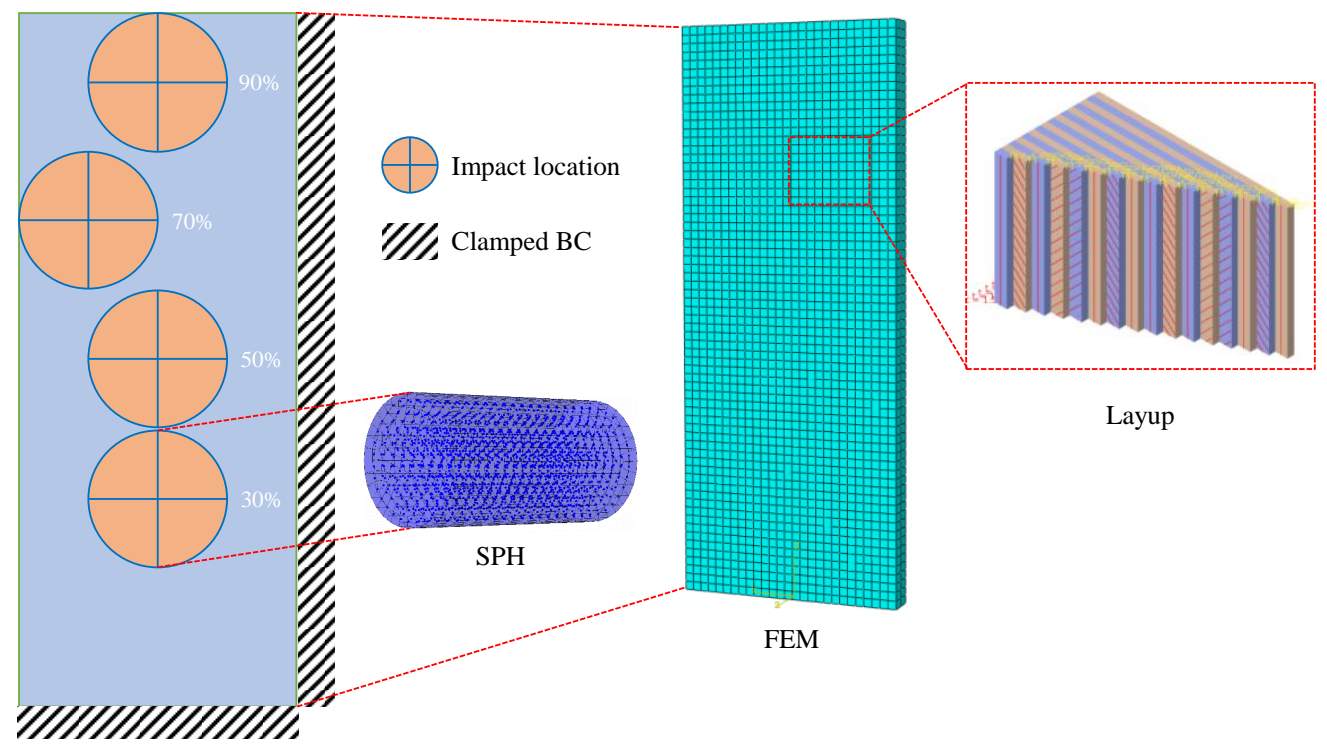

Figure 2. SPH/FEM model and simulation cases for bird-strike impact (BC: boundary condition).

Once the structural configuration is fixed, the impact location and the boundary condition are the two most influential factors that govern the impact response and damage. Therefore, the two considered strategies (the impact location and the boundary condition) for surrogate testing of fan blade structure are investigated by six simulation cases, which are listed as follows:

(a) Impact symmetrically on $30 \%$ height of the plate, with the root clamped only;

(b) Impact symmetrically on $50 \%$ height of the plate, with the root clamped only;

(c) Impact eccentrically on $70 \%$ height of the plate, with the root clamped only;

(d) Impact symmetrically on $90 \%$ height of the plate, with the root clamped only;

(e) Impact symmetrically on 50\% height of the plate, with both the root and the tip clamped;

(f) Impact eccentrically on 70\% height of the plate, with both the root and one side edge clamped.

To be intuitive, the six simulation cases are shown as Figure 3. Among the four locations, 30\%, 50\%, and $90 \%$ heights of the blade span are distributed on the axis of symmetry, while the $70 \%$ height of span is eccentrically located, which is for the purpose of including the torsional effect on the impact responses. In the (a), (b) and (d), (e) cases, both the impact loading and the boundary condition are symmetric, which is a commonly used manner for impact-resistance evaluation [26,27]. However, in the (c) and (f) cases, the impact loading is asymmetric, of which the aim is to examine the effect of the asymmetric boundary condition. In fact, in the component-level mechanism experiment, one purpose is to evaluate the impact resistance, and the other is to be close to the actual load-carrying situation as far as possible. In such a way, the mechanism experiment can be more meaningful. To be brief, three different boundary conditions are involved in present study:

(a) The root clamped only;

(b) Both the root and tip clamped;

(c) Both the root and one side edge clamped. 

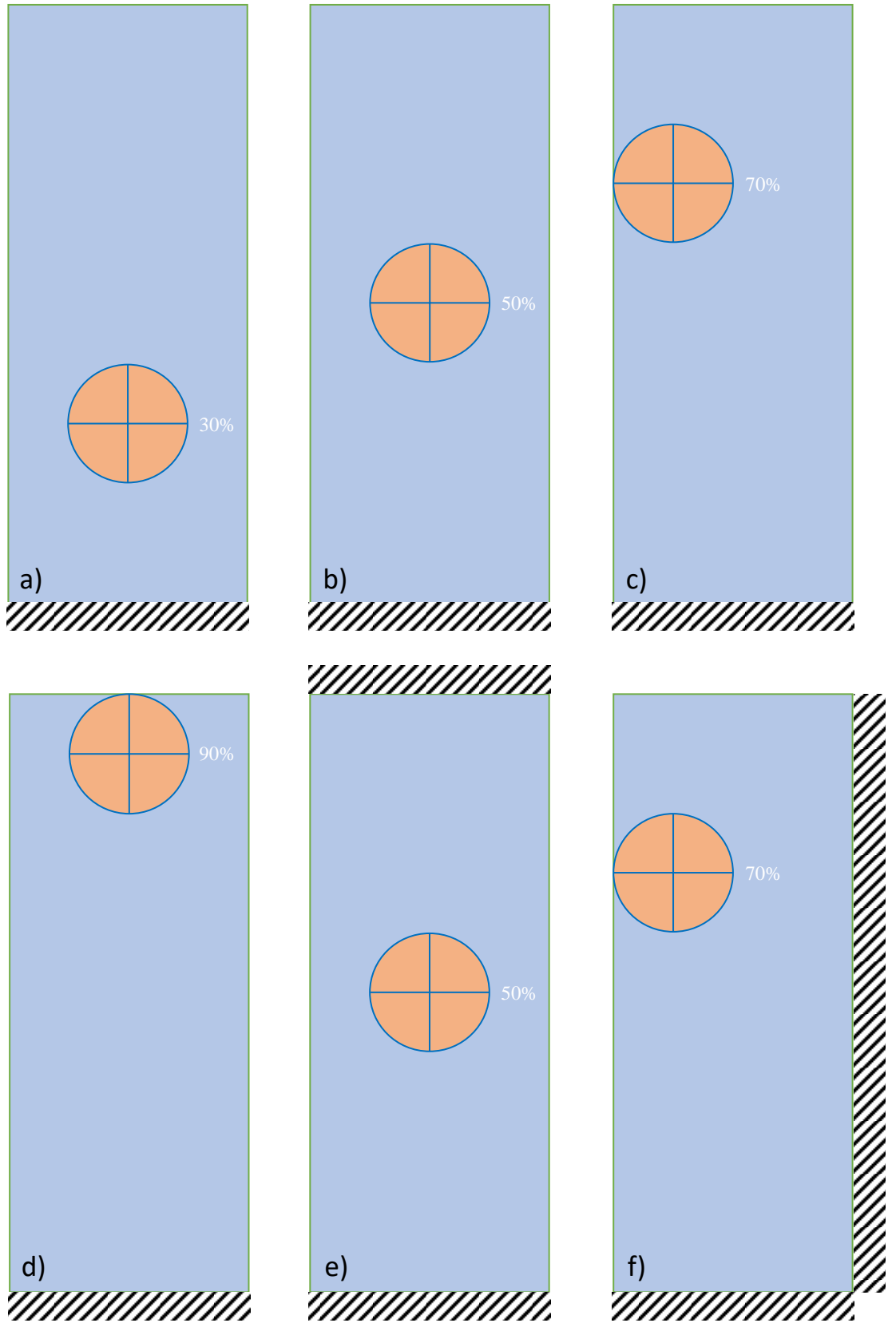

Figure 3. The six considered simulation cases with different impact locations and boundary conditions. (a) 30\%, root clamped; (b) 50\%, root clamped; (c) 70\%, root clamped; (d) $90 \%$, root clamped; (e) $50 \%$, root \& tip clamped; (f) $70 \%$, root \& side clamped.

\section{Results and Discussion}

Impact damage distributions of the considered six cases with the bird-strike process finished at $5 \mathrm{~ms}$ are as illustrated in Figure 4. Herein, the matrix-tension damages are used, which are presented as visible cracks in experiments and are convenient for detection. Firstly, it can be seen that the plate's roots experienced severe damage the 30\% and 50\% height cases, as shown in (a) and (b), respectively. As indicated from (a) to (c), with the different impact locations moved from the root end to the tip end, the damages at the roots can be decreased in the cases with the root clamped only. For example, at the $70 \%$ height case, the root experienced less damage and the damage distribution was not symmetric due to the eccentric impact location. In particular, when up to $90 \%$ height (impact near the blade tip), the impact contact area and the middle of the plate experienced more severe 
damage than the root, which can be considered as more favourable damage distribution for experimental observation and mechanism investigation.

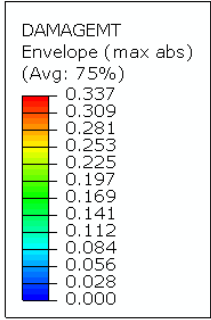

a)
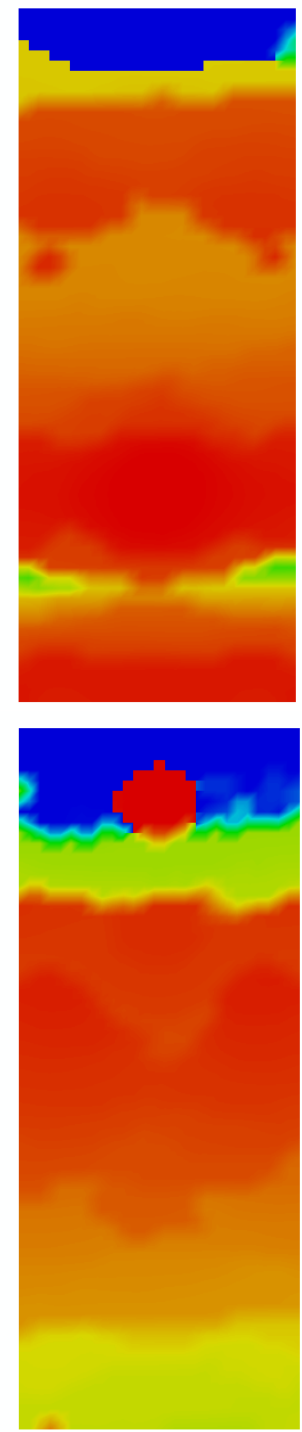

b)
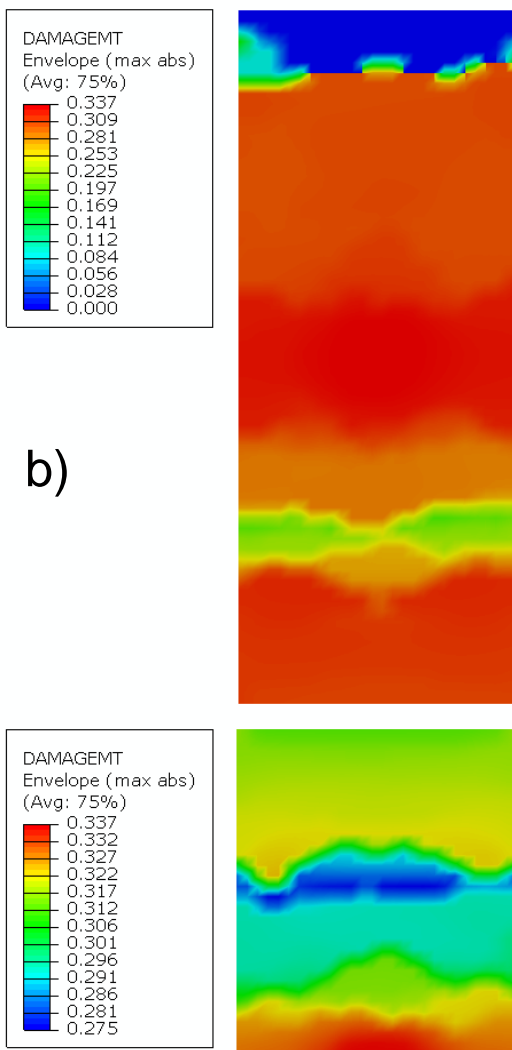

e)

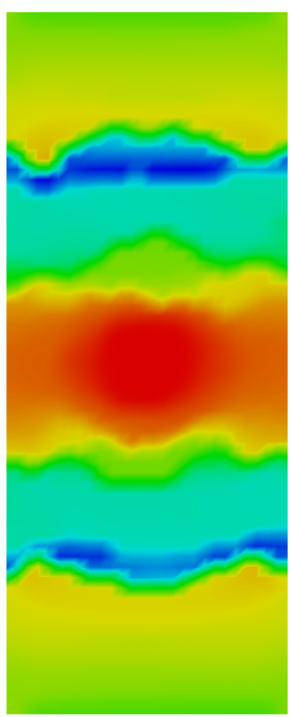

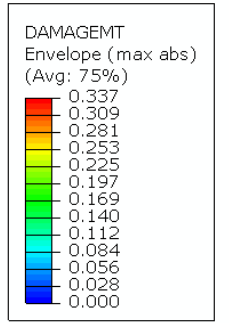

c)
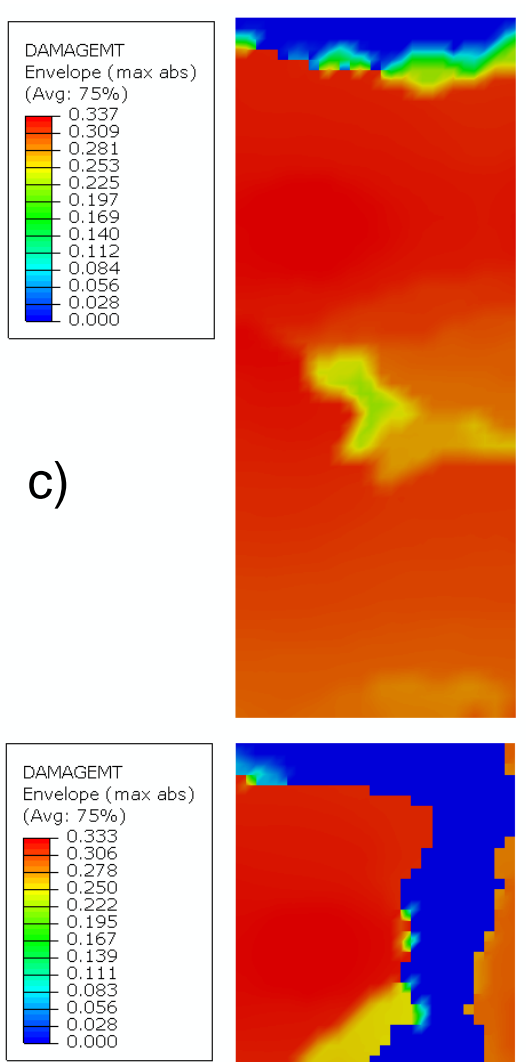

f)

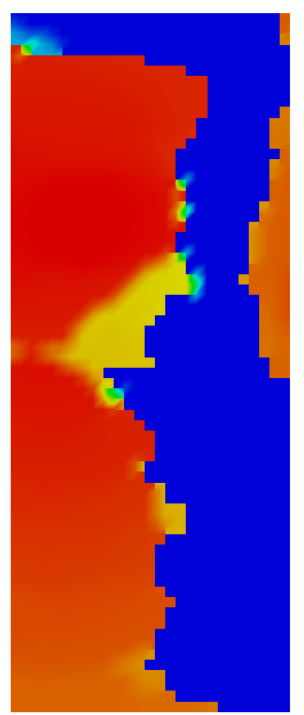

Figure 4. Matrix-tension damage distributions of the considered six cases at $5 \mathrm{~ms}$. (a) 30\%, root clamped; (b) 50\%, root clamped; (c) 70\%, root clamped; (d) 90\%, root clamped; (e) 50\%, root \& tip clamped; (f) 70\%, root \& side clamped.

The second considered strategy was to change the boundary condition. To be different from the first one with root clamped only, the second considered boundary condition was applied on both the root and the tip to form a clamped-clamped case. Figure $4 \mathrm{e}$ shows the matrix-tension damage distribution of the $50 \%$ height impact with the clamped-clamped boundary condition. In this case, all regions of the plate will carry the impact loading. It can be seen that the majority of the plate was largely damaged, with the middle region being the most severe. Then, the third boundary condition was clamping the root and one side edge. Figure $4 \mathrm{f}$ shows the matrix-tension damage distribution of the third boundary condition, which eccentrically impacted at 70\% height. It can be seen that the majority of the impacted free edge experienced the large damage, while the damages in the both clamped boundaries were relatively slight. Therefore, it can be concluded that the boundary condition has a significant effect on the impact damage mode. To be more similar with the failure case of a real fan blade, the flat plate, with the root and one side edge clamped, can be considered as the favourable choice to conduct the surrogate bird-strike testing. In fact, in the boundary conditions of (a) to (e) cases, the clamped plates behave as the 
slender structure, and hence the clamped regions experienced large damage. However, in the boundary condition of (f) case, the clamped plate behaves as the short and fat structure, and hence the clamped regions are strong enough to resist the excessive damage.

Although the matrix-tension damage is easy to detect, the other damage modes are also critical to evaluate the strength degradation. Figure 5 shows the fibre-tension, fibrecompression and matrix compression damages of the eccentric impact case with the root and one side edge clamped. It can be seen that these three damages are locally distributed and can even be neglected. In the bird-strike test of a real composite fan blade, the fibre breakage hardly occurs. Therefore, it is further verified the effectiveness of the eccentric impact case with the root and one side edge clamped, for the surrogate bird-strike testing of composite fan blades.

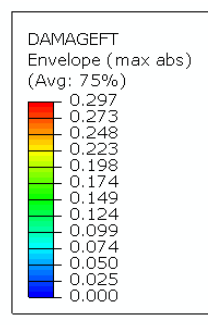

a)
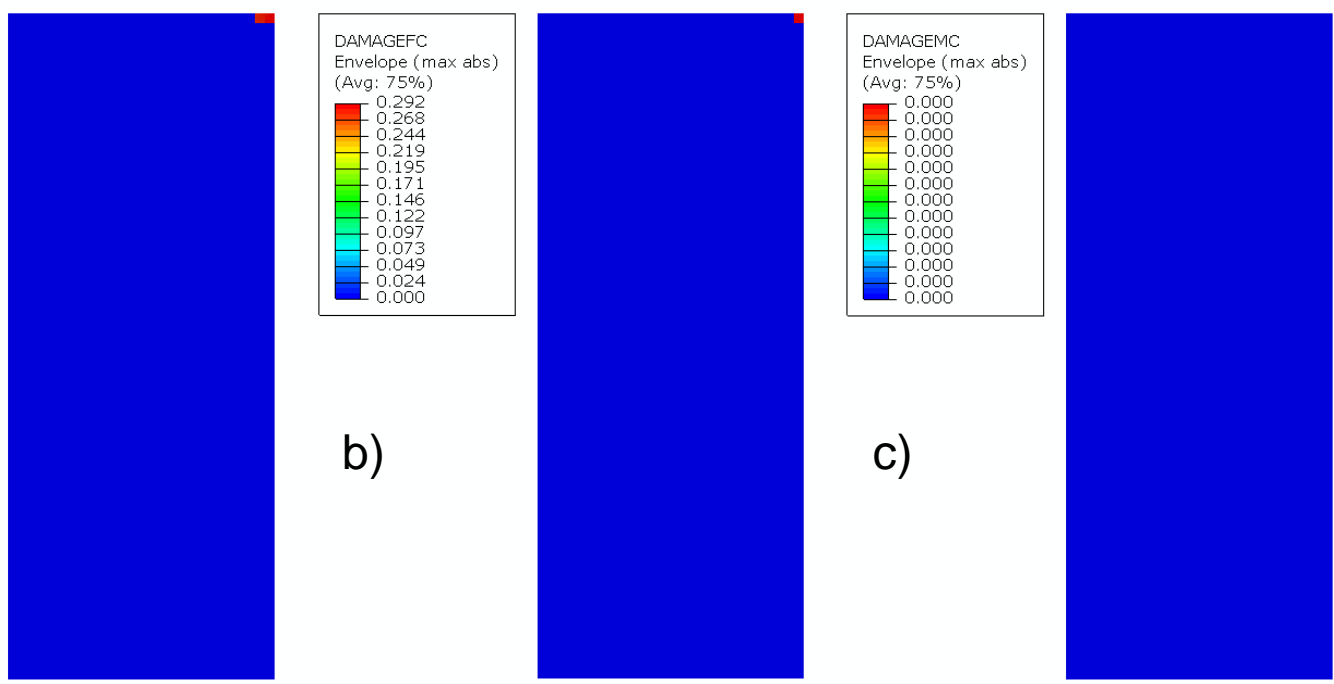

Figure 5. Other three damage distributions of the eccentric impact case with the root and one side edge clamped: (a) fibre tension, (b) fibre compression and (c) matrix compression.

In the bird-strike test of real composite fan blade, the bird projectile can impact on the blade or can be sliced by the leading edge of the fan blade. Figure 6 plots the maximum impact deflections of the six simulated plates with the increasing time. On the whole, as the clamped boundary condition reinforced, the maximum impact deflections of the composite plates decreased. Figure 7 plots the deformation series of the bird projectile impacting the composite plate with the root and one side edge clamped boundary condition. It can be seen that the bird projectile firstly contacts the plate and then spreads out on the plate surface in this boundary condition. The majority of the impact energy is absorbed by the composite plate. Such results indicate that the present impact case can simulate the bird impacting on the blade surface, but cannot simulate the bird being sliced. Besides, Figure 8 plots the deformation magnitudes of the composite plate with the root and one side edge clamped boundary condition during the bird impact. It can be seen that the impact region experienced large deformation during the impact process. Such phenomenon is also similar with the dynamic behaviours of fan blades subjected to bird-strike loads.

Furthermore, Figure 9 gives the matrix-tension damages of the composite plate, with the root and one side edge clamped boundary condition, under three different impact velocities: (a) $100 \mathrm{~m} / \mathrm{s}$, (b) $120 \mathrm{~m} / \mathrm{s}$, and (c) $140 \mathrm{~m} / \mathrm{s}$. It can be seen that the maximum damages increase as the impact velocity increases; however, the damage distributions are still preferable under different velocities. 


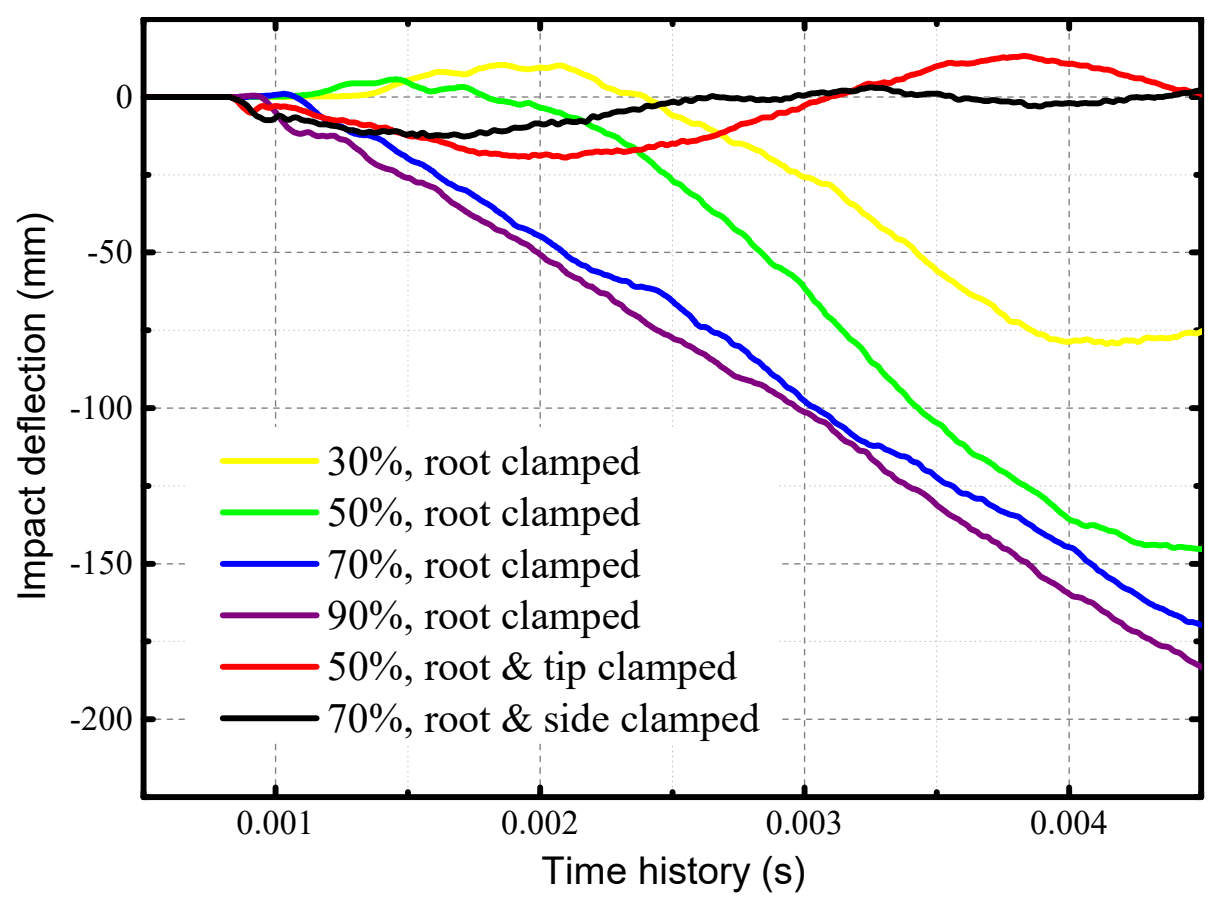

Figure 6. The maximum impact deflections of the six simulated plates with the increasing time.
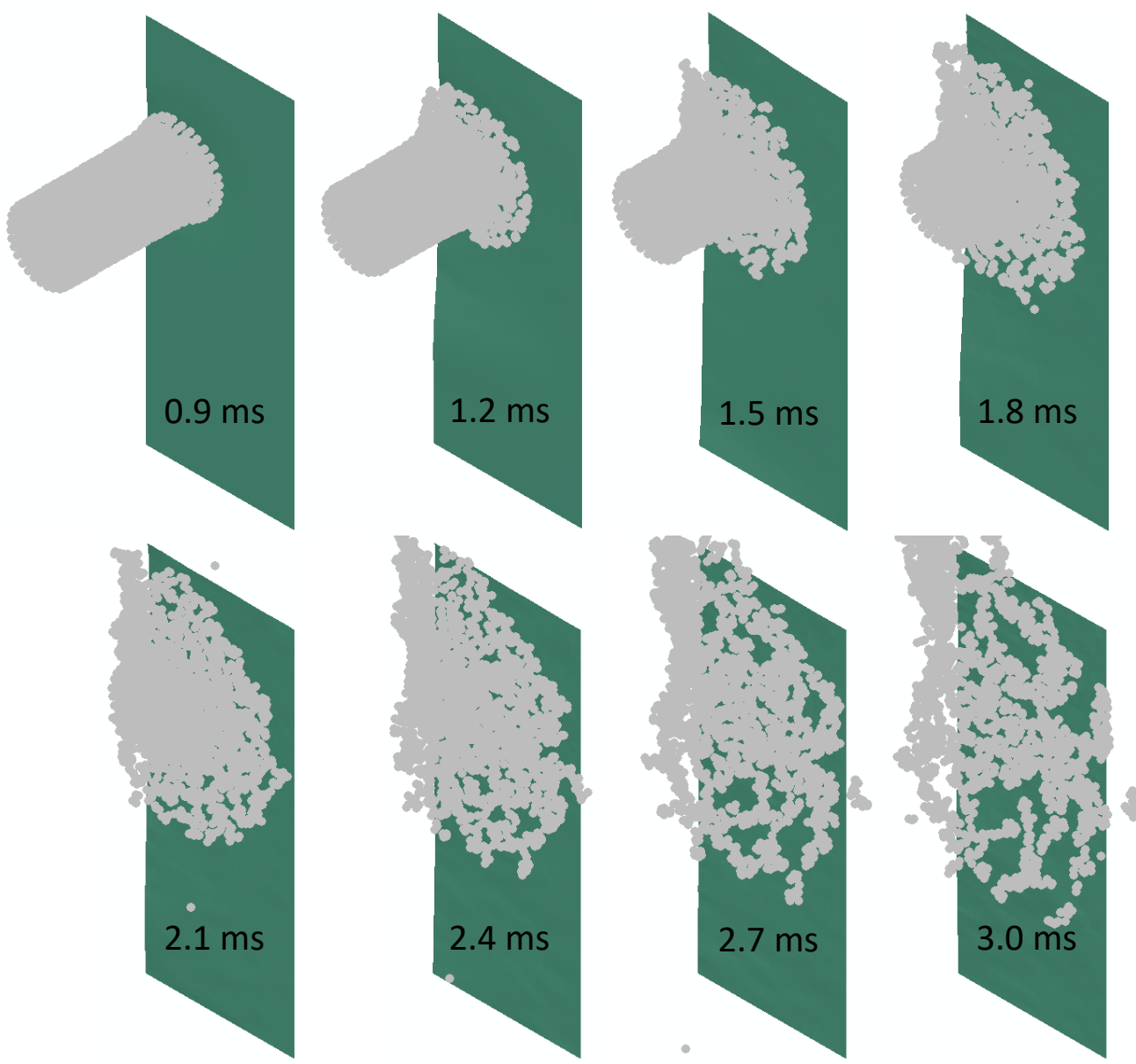

Figure 7. Deformation series of the bird projectile impacting the composite plate with the root and one side edge clamped boundary condition. 


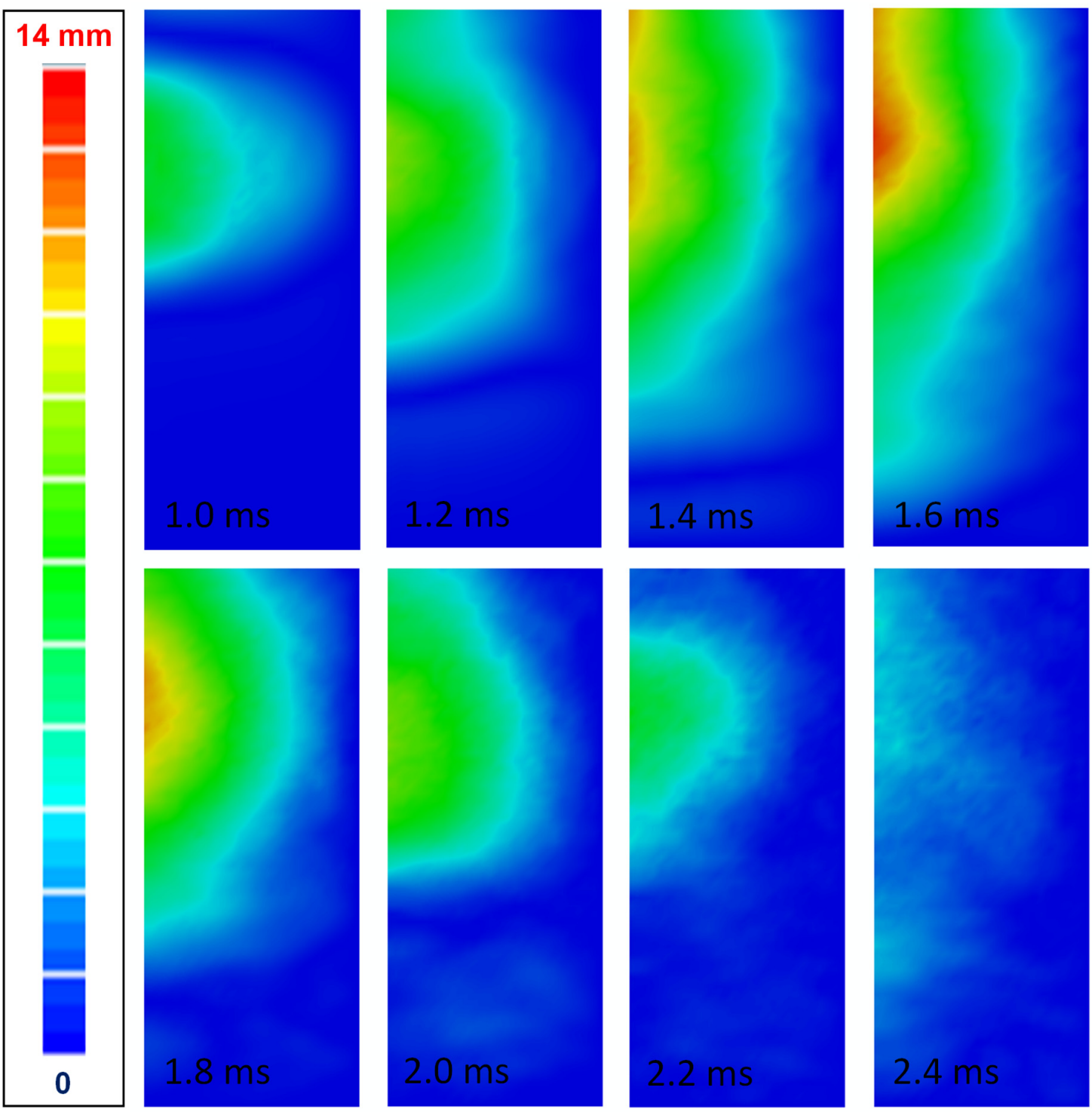

Figure 8. Deformation magnitudes of the composite plate with the root and one side edge clamped boundary condition during the bird impact.

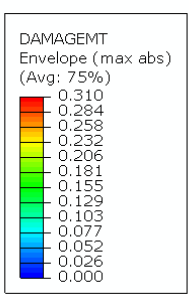

a)

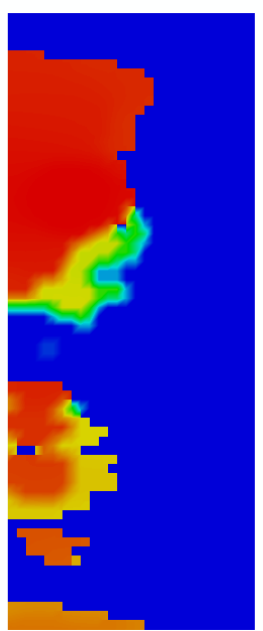

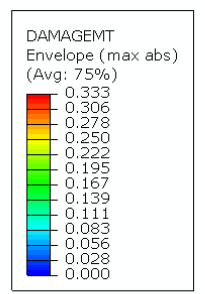

b)
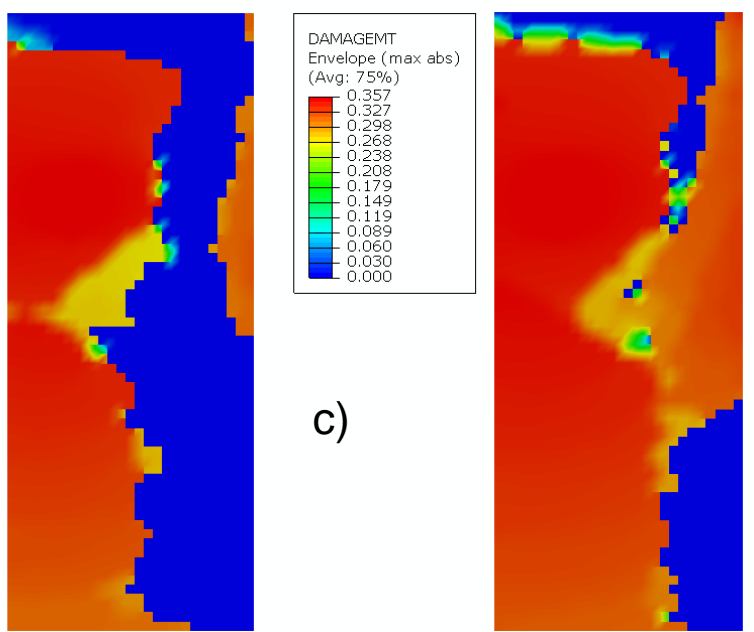

Figure 9. Matrix-tension damages of the composite plate with the root and one side edge clamped boundary condition under different impact velocities: (a) $100 \mathrm{~m} / \mathrm{s}$, (b) $120 \mathrm{~m} / \mathrm{s}$, and (c) $140 \mathrm{~m} / \mathrm{s}$. 
Lastly, it needs to mention that the present strategy can only mimic the case that the bird projectile impacts on the blade surface, and hence, the dominant failure is the in-plane damage. In the future study, a slice of the bird projectile by the composite plate needs to be considered, where the delamination and debond of the composite laminate should be involved.

\section{Conclusions}

To pursue desirable impact damage distributions of the simplified flat plate to mimic the real composite fan blades, SPH/FEM modelling and simulation were conducted to examine two different strategies: (1) the boundary condition; (2) the impact location. Simulation results can help researchers and investigators achieve the suitable experiment design in simplified bird-strike testing. The following conclusions can be reached:

(1) The impact location has an important influence on the impact damage distributions of the flat blade-like composite plate. Impacted at the location near the tip, the damage at the blade root became smaller than the impact contact area, which will be more convenient for damage mechanism observation in simplified experiments.

(2) The effect of boundary conditions on bird-strike impact damage distributions of the blade-like composite plates is very remarkable. The damage distributions of the boundary condition with the root and one side edge clamped is more similar with the case of real fan blades, which can successfully avoid the root failure and bridge the simplified experiments and failure prediction of real fan blades.

Therefore, in the future simplified experimental work, different boundary conditions (e.g., the case clamping both the root and one side edge in the present simulation) will be the promising configurations for damage mechanism study, which can avoid the undesirable failure modes at the blade root. Such simplification practice, for twisted blades, can provide valuable reference significance for future surrogate testing, by facilitating the mechanism investigation into the composite materials, and bridging from the component-level failure mechanism to the structure-level crashworthiness evaluation.

Author Contributions: Conceptualization, Y.Z. (Yadong Zhou); Methodology, Y.Z. (Yadong Zhou); Software, Y.Z. (Yadong Zhou); Validation, Y.Z. (Yuemei Zhang) and H.Z. (Haitao Zhang); Formal Analysis, Y.Z. (Yadong Zhou); Investigation, Y.Z. (Yadong Zhou); Resources, Y.S.; Data Curation, Y.Z. (Yadong Zhou); Writing-Original Draft Preparation, Y.Z. (Yadong Zhou); Writing—Review \& Editing, Y.Z. (Yadong Zhou); Visualization, Y.Z. (Yadong Zhou); Supervision, Y.S. and Y.Z. (Yadong Zhou); Project Administration, H.Z. (Haijun Zeng) and K.Y.; Funding Acquisition, Y.S. and Y.Z. (Yadong Zhou). All authors have read and agreed to the published version of the manuscript.

Funding: This work was supported by the Joint Fund of National Natural Science Foundation of China and Civil Aviation Administration of China (U2033202, U1333119), the National Science and Technology Major Project (2017-VIII-0003-0114, 2017-VIII-0002-0113), the National Natural Science Foundation of China (62076126) and the Fundamental Research Funds for the Central Universities (1007-XAA21002).

Data Availability Statement: The authors are willing to share the data underlying the findings of this work, and the data used to support the findings of this study are included within the article.

Acknowledgments: The authors are very grateful to the Editor and the anonymous Reviewers whose insightful and constructive comments greatly helped us to improve the manuscript.

Conflicts of Interest: The authors declare that they have no conflicts of interest.

\section{References}

1. Abrate, S. Soft impacts on aerospace structures. Prog. Aeronaut. Sci. 2016, 81, 1-17. [CrossRef]

2. Shupikov, A.; Ugrimov, S.; Smetankina, N.V.; Yareshchenko, V.G.; Onhirsky, G.G.; Ukolov, V.P.; Samoylenko, V.F.; Avramenko, V.L. Bird Dummy for Investigating the Bird-Strike Resistance of Aircraft Components. J. Aircr. 2013, 50, 817-826. [CrossRef]

3. Guida, M.; Marulo, F.; Meo, M.; Russo, S. Certification by birdstrike analysis on C27J fullscale ribless composite leading edge. Int. J. Impact Eng. 2013, 54, 105-113. [CrossRef] 
4. Meguid, S.A.; Mao, R.H.; Ng, T.Y. FE analysis of geometry effects of an artificial bird striking an aeroengine fan blade. Int. J. Impact Eng. 2008, 35, 487-498. [CrossRef]

5. Sinha, S.K. Transient Response of a Multilayered Composite Rotating Airfoil under Slicing-Impact Loading. AIAA J. 2014, 52, 2701-2711. [CrossRef]

6. Muir, E.R.; Friedmann, P.P. Forced and Aeroelastic Responses of Bird-Damaged Fan Blades: A Comparison and Its Implications. J. Aircr. 2016, 53, 561-577. [CrossRef]

7. Liu, J.; Zhong, D.; Li, Y.; Tang, Z.; Gao, X.; Zhang, Z.; Huang, F. Numerical simulation and test on damage of rotary engine blades impacted by bird. Int. J. Crashworthiness 2018, 1-15. [CrossRef]

8. Zhou, Y.; Sun, Y.; Cai, W. Bird-striking damage of rotating laminates using SPH-CDM method. Aerosp. Sci. Technol. 2019, 84, 265-272. [CrossRef]

9. Zhou, Y.; Sun, Y.; Huang, T. Impact responses of slender composite plates for bird-strike testing of fan blades. Lat. Am. J. Solids Struct. 2019, 16. [CrossRef]

10. Zhou, Y.; Sun, Y.; Huang, T. Impact-Damage Equivalency for Twisted Composite Blades with Symmetrical Configurations. Symmetry 2019, 11, 1292. [CrossRef]

11. Giannopoulos, I.K.; Yasaee, M.; Maropakis, N. Ballistic Impact and Virtual Testing of Woven FRP Laminates. J. Compos. Sci. 2021, 5, 115. [CrossRef]

12. Sartip, Z.; Jayantha, E.; Wahid, F.; Jinsong, L. A novel hybridised composite sandwich core with Glass, Kevlar and Zylon fibres-Investigation under low-velocity impact. Int. J. Impact Eng. 2020, 137, 103430. [CrossRef]

13. Sartip, Z.; Jayantha, E.; Wahid, F.; Jinsong, L.; Peter, S. Behaviour of continuous fibre composite sandwich core under low-velocity impact. Thin-Walled Struct. 2021, 158, 107157. [CrossRef]

14. Wu, H.; Fan, G. An overview of tailoring strain delocalization for strength-ductility synergy. Prog. Mater. Sci. 2020, 113, 100675. [CrossRef]

15. Wu, H.; Huang, M.; Li, X.; Xia, Y.; Wang, Z.; Fan, G. Temperature-dependent reversed fracture behavior of multilayered TiBw/Ti-Ti(Al) composites. Int. J. Plast. 2021, 141, 102998. [CrossRef]

16. Mao, R.; Meguid, S.A.; Ng, T.Y. Finite Element Modeling of a Bird Striking an Engine Fan Blade. J. Aircr. 2007, 44, 583-596. [CrossRef]

17. Hou, J.P.; Ruiz, C. Soft body impact on laminated composite materials. Compos. Part A 2007, 38, 505-515. [CrossRef]

18. Nishikawa, M.; Hemmi, K.; Takeda, N. Finite-element simulation for modeling composite plates subjected to soft-body, highvelocity impact for application to bird-strike problem of composite fan blades. Compos. Struct. 2011, 93, 1416-1423. [CrossRef]

19. Handschuh, K.M.; Miller, S.G.; Sinnott, M.J.; Kohlman, L.W.; Roberts, G.D.; Pereira, J.M.; Ruggeri, C.R. Materials, Manufacturing and Test Development of a Composite Fan Blade Leading Edge Subcomponent for Improved Impact Resistance; Seattle, W.A., Ed.; Society for the Advancement of Materials and Process Engineering: Covina, CA, USA, 2014.

20. Liu, L.; Luo, G.; Chen, W.; Zhao, Z.; Huang, X. Dynamic Behavior and Damage Mechanism of 3D Braided Composite Fan Blade under Bird Impact. Int. J. Aerosp. Eng. 2018, 2018, 1-16. [CrossRef]

21. Vignjevic, R.; Orłowski, M.; De Vuyst, T.; Campbell, J.C. A parametric study of bird strike on engine blades. Int. J. Impact Eng. 2013, 60, 44-57. [CrossRef]

22. Guida, M.; Marulo, F.; Polito, T.; Meo, M.; Riccio, M. Design and Testing of a Fiber-Metal-Laminate Bird-Strike-Resistant Leading Edge. J. Aircr. 2009, 46, 2121-2129. [CrossRef]

23. Smojver, I.; Ivančević, D. Bird strike damage analysis in aircraft structures using Abaqus/Explicit and coupled Eulerian Lagrangian approach. Compos. Sci. Technol. 2011, 71, 489-498. [CrossRef]

24. Stamoulis, K.; Georgantzinos, S.K.; Giannopoulos, G.I. Damage characteristics in laminated composite structures subjected to low-velocity impact. Int. J. Struct. Integr. 2019, 11, 670-685. [CrossRef]

25. Long, S.; Mu, X.; Liu, Y.; Wang, H.; Zhang, X.; Yao, X. Failure modeling of composite wing leading edge under bird strike. Compos. Struct. 2021, 255, 113005. [CrossRef]

26. AlOmari, A.S.; Al-Athel, K.S.; Arif, A.F.M.; Al-Sulaiman, F.A. Experimental and Computational Analysis of Low-Velocity Impact on Carbon-, Glass- and Mixed-Fiber Composite Plates. J. Compos. Sci. 2020, 4, 148. [CrossRef]

27. Zhou, Y.; Sun, Y.; Huang, T. Bird-Strike Resistance of Composite Laminates with Different Materials. Materials 2020, 13, 129. [CrossRef] 